\title{
The influence of comorbidity on the prevalence of pressure ulcers in geriatric patients
}

\author{
Neloska Lenche ${ }^{1 *}$, Damevska Katerina ${ }^{2}$, Andjelka Nikolchev ${ }^{1}$, Pavleska Lidija ${ }^{1}$, Petreska-Zovic Biljana ${ }^{1}$ and Kostov Milenko ${ }^{3}$ \\ ${ }^{1}$ PHI Gerontology Institute “13 November Skopje”, Skopje \\ ${ }^{2}$ University Clinic of Dermatology, Medical Faculty, Skopje \\ ${ }^{3}$ University Clinic of Neurosurgery, Medical Faculty, Skopje
}

\begin{abstract}
Background: Pressure ulcers are a common problem among older adults in all health care settings. A number of contributing factors are associated with pressure ulcers.

Aim: The aim of the present study was to determine the prevalence of pressure ulcers in patients hospitalized in long term care facility, and to examine the influence of comorbidity on the prevalence of pressure ulcers.

Methods: Data were retrospectively collected, and included demographic characteristics and comorbidities. For each patient with PU we collected PU characteristics (location, number of PU per patient, and stage).

Results: In the study period, 2099 patients were hospitalized; and 1289 patients (61.4\%) were women. Median age was 76.32 years. The total pressure ulcer prevalence was $12.19 \%$. The number of comorbidities was higher in the patients with PU, compared with patients without PU ( $\mathrm{p}<0.001)$. The prevalence of PU was significantly influenced by diabetes $(\mathrm{p}=0,021)$ and neurological disorders $(\mathrm{p}=0,051)$.

Conclusion: Our data suggest that the comorbidities play an important role in the pathogenesis of the pressure sores.
\end{abstract}

\section{Background}

A pressure ulcer $(\mathrm{PU})$ is localized injury to the skin and/or underlying tissue usually over a bony prominence, as a result of pressure or pressure in combination with shear. It leads to ischemia, cell death, progressive destruction and necrosis of theunderlying soft tissues [1].

It is estimated that the prevalence of PU has doubled in recent years [2], andthe incidence has increased by $80 \%$ between 1995 and 2008 [3].

Pressure ulcers are among the most common conditions encountered in patients requiring institutional care. The prevalence of PU ranges from 1 to $18 \%$ of in-patients, from 3 to $29 \%$ of those admitted to long-term settings, and $0 \%$ to $17 \%$ in home care settings [3-5].

They are a common problem among older adults in all health care settings, including acute hospitals, nursing homes and geriatric and palliative centers (3). In a study performed in Sweden, $97 \%$ of patients with PU were 65 years and more, $63 \%$ of them were older than 80 years [6].

Prevalence and incidence estimates of PU in the elderlyvary by setting, ulcerstage, and length of follow-up [3,7]. For example, many epidemiological studies have elected not to include stage 1 ulcers since they are difficult to reliably detect.

A broad range of factors have an influence ondevelopment of PUs in long-term care residents [5]. Mobility limitation, incontinence, nutritional status, pain, infectious complications, prolonged hospitalizations and altered consciousness are the most consistently reported risk factors for pressure ulcers [8].

Although previous studies have suggested that certain conditions, such as spinal cord injuries, hip fractures, cardiovascular disease, and diabetes, increase the likelihood that a patient will develop a PU, the role of thecomorbidity status in the development of PUs in geriatric hospitals is rarely investigated.

The objective of this study was to investigate the prevalence of PUs in a geriatric hospitaland explore the possible connections between prevalence rate and comorbidity status.

\section{Material and method}

The study was carried out at the Geriatric and Palliative Care Hospital in Skopje, an institution that serves the 1200000 population, offering geriatric and palliative care. It is the largest specialized geriatric and palliative hospital in the country and exclusively attends to patients through the Public Health System. The study design was approved by the Hospital Ethics Committee. Informed consent was waived because of the study's observational nature.

Correspondence to: Neloska Lenche, PHI Gerontology Institute "13 November Skopje”, Skopje, E-mail: neloskal@gmail.com

Key words: pressure ulcer, comorbidities, prevalence, diabetes mellitus, neurologic diseases

Received: May 10, 2016; Accepted: June 06, 2016; Published: June 10, 2016 
We included all consecutively admitted patients from October 2014 to November 2015.

We collected data using a case report form specifically created for this study, recording information about demographics, main diagnosis, length of stay, presence of PU and PU characteristics.

The Braden scale was used to assess the risk of developing PUs. The total score can range from 6 to 23 with a lower score indicating a higher risk [9]. The risk of PUs increases in patients with ascore $\leq 12$ points (cut-off point). The grading system of the EPUAP was used [1].

Descriptive statistics were used to describe the study population, with continuous outcomes summarized as a mean and range, and categorical outcomes presented as a percent. We performed Chi-square tests for continuous variables and independent $t$-tests for continuous variables. $P$-values $<0.05$ were considered statistically significant.

\section{Results}

During the study period, two thousand and ninety-ninepatients were consecutively admitted to the Geriatric Hospital. Their baseline characteristics are shown in Table 1 . The mean age was 76,32 years, SD 11,202 . There was a female predominance ( 1289 or $61.4 \%$ ).

A total of 540 PUs were presented in 256 patients. 136 of 256 patients (53.1\%) developed one PU, 49 patients (19.2\%) developed two, 39 patients (15.3\%) developed three and 32 patients (12.4\%) developed more than four PUs (Figure 1).

The total pressure ulcer prevalence was12.19\% (256 out of 2099).

Table 2 presents the anatomical distribution of the detected pressure ulcers $(\mathrm{N}=540)$ and reveals that the most common body sites

Table 1. Baseline characteristics of patient population, according to the presence/absence of PU.

\begin{tabular}{|l|c|c|c|c|c|c|c|}
\hline Gender & \multicolumn{2}{|c|}{} & \multicolumn{5}{|c|}{ Age } \\
\hline \multirow{3}{*}{$\begin{array}{l}\text { PU } \\
\text { absent }\end{array}$} & Male & 724 & 39.28 & 74,63 & 11,697 & 25 & 103 \\
\cline { 2 - 8 } & Female & 1119 & 60.71 & 77,41 & 10,717 & 22 & 101 \\
\cline { 2 - 8 } & Total & 1843 & 87.80 & 76,32 & 11,192 & 22 & 103 \\
\hline \multirow{2}{*}{$\begin{array}{l}\text { pu } \\
\text { present }\end{array}$} & Male & 86 & 33.59 & 74,50 & 12,234 & 38 & 97 \\
\cline { 2 - 8 } & Female & 170 & 66.40 & 77,34 & 10,702 & 37 & 95 \\
\cline { 2 - 8 } & Total & 256 & 12.19 & 76,38 & 11,296 & 37 & 97 \\
\hline \multirow{3}{*}{ Total } & Male & 810 & 38.58 & 74,61 & 11,748 & 25 & 103 \\
\cline { 2 - 8 } & Female & 1289 & 61.41 & 77,40 & 10,710 & 22 & 101 \\
\cline { 2 - 8 } & Total & 2099 & 100.00 & 76,32 & 11,202 & 22 & 103 \\
\hline
\end{tabular}

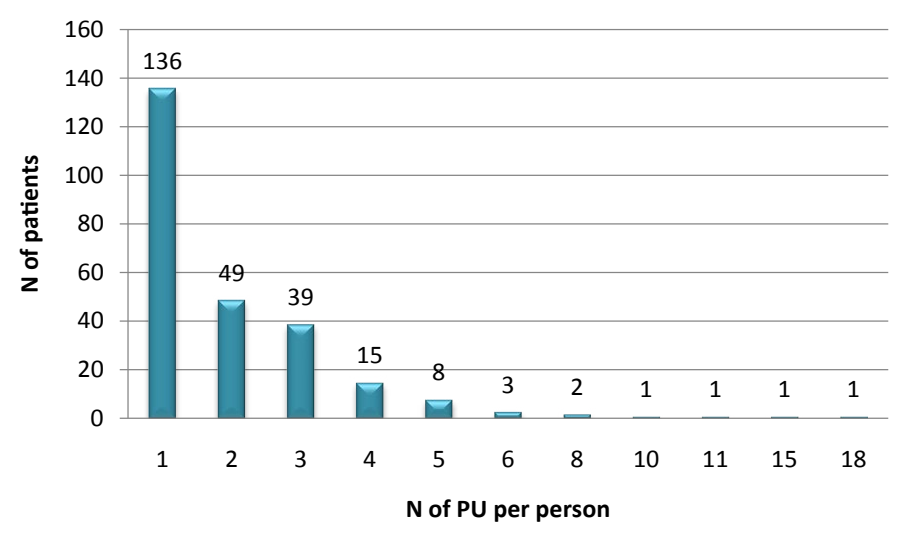

Figure 1. Distribution of PU per person (Total 540).
Table 2. Pressure ulcers stages by site.

\begin{tabular}{|l|c|c|c|c|c|c|c|}
\hline & St 1 & St 2 & St 3 & St 4 & Echar & STDI & Total \\
\hline Sacrum & 20 & 76 & 25 & 23 & 9 & 0 & 153 \\
\hline Hip & 7 & 34 & 4 & 10 & 3 & 0 & 58 \\
\hline Heel & 28 & 75 & 10 & 8 & 18 & 1 & 140 \\
\hline Gluteal & 5 & 43 & 4 & 3 & 3 & 0 & 58 \\
\hline Back & 2 & 13 & 4 & 0 & 1 & 0 & 20 \\
\hline Scapula & 2 & 8 & 3 & 2 & 2 & 0 & 17 \\
\hline Elbow & 1 & 7 & 1 & 0 & 1 & 0 & 10 \\
\hline Malleolus & 9 & 17 & 4 & 0 & 6 & 0 & 36 \\
\hline Other & 4 & 23 & 7 & 5 & 9 & 0 & 48 \\
\hline Total & 78 & 296 & 62 & 51 & 52 & 1 & 540 \\
\hline
\end{tabular}

SDTI-suspected deep-tissue injury

Table 3. Number of comorbidities per person.

\begin{tabular}{|c|c|c|}
\hline & $\begin{array}{c}\text { PU present } \\
\text { N (\%) }\end{array}$ & $\begin{array}{c}\text { PU absent } \\
\text { N (\%) }\end{array}$ \\
\hline 0 & $4(1.6)$ & $60(3.3)$ \\
\hline 1 & $40(15.6)$ & $335(18.2)$ \\
\hline 2 & $85(33.2)$ & $587(31.9)$ \\
\hline 3 & $88(34.4)$ & $535(29.0)$ \\
\hline 4 & $26(10.2)$ & $251(13.6)$ \\
\hline 5 & $11(4.3)$ & $61(3.3)$ \\
\hline 6 & $1(0.4)$ & $13(0.7)$ \\
\hline 7 & $1(0.4)$ & $1(0.1)$ \\
\hline Total & 256 & 1843 \\
\hline
\end{tabular}

of PUs were the sacrum and the heel, and the most common stage was Stage 2.

Table 3 shows the number of comorbidities per person. There was a positive association between the number of comorbidities and PU prevalence $\left(\chi^{2}=15,578 ; \mathrm{p}<0.01\right)$.

Table 4 presents a significant connection between the presence of $\mathrm{PU}$ and a range of individual comorbidities. The two factors with the greatest association with the presence of a pressure ulcer were diabetes mellitus ( $\mathrm{p}=0,021 ; \mathrm{OR}=1.082,95 \% \mathrm{CI} 1.052-1.894)$ and neurological diseases ( $p=0,051 ; O R=1,344,95 \%$ CI $0.960-1.882)$. We also noted that there was a significant connection between the presence of $\mathrm{PU}$ and the Braden score $(\mathrm{p}<0,00001)$.

\section{Discussion}

This study revealed that PUs constitute a significant problem in geriatric and palliative patients. The reported prevalence of PUs in geriatric patients vary widely from $9 \%-32 \%$ [3-5]. This difference most likely reflects the variation in the characteristics of the cases, PU classifications, inclusion criteria, and data collection methods. The prevalence rate detected in this study of $12.19 \%$ was generally consistent with international studies employing similar methodology.

The significant variability in PU prevalence and incidence in longterm care settings for older people suggests that opportunities exist to improve outcomes for persons at risk for PU [10].

Pressure ulcers occurrence presents a heavy burden on the medical services. The estimated cost of treating each case of PUs ranges from $\$ 37800$ to $\$ 70000$ [11].

The presence of a pressure ulcer constitutes a geriatric syndrome consisting of multifactorial pathological conditions. The accumulated effects of impairment due to immobility, nutritional deficiency and chronic diseases involving multiple systems predispose the aging skin 
Table 4. Differences between patients with and without a pressure ulcer.

\begin{tabular}{|c|c|c|c|c|c|}
\hline & $\begin{array}{l}\text { PU absent } \\
N=1843\end{array}$ & $\begin{array}{l}\text { PU present } \\
\quad \mathrm{N}=256\end{array}$ & $\begin{array}{c}\text { P-value } \\
\text { (chi-square) }\end{array}$ & OR & $95 \% \mathrm{CI}$ \\
\hline \multirow{2}{*}{ Diabetes mellitus, $n(\%)$} & \multirow{2}{*}{$400(21.7)$} & \multirow{2}{*}{$72(28.1)$} & 0.021 & \multirow{2}{*}{1.412} & \multirow{2}{*}{$1.052-1.894$} \\
\hline & & & -5.317 & & \\
\hline \multirow{2}{*}{ HTA, $n(\%)$} & \multirow{2}{*}{$1075(58.3)$} & \multirow{2}{*}{$162(63.3)$} & 0.131 & \multirow{2}{*}{1.231} & \multirow{2}{*}{$0.939-1.614$} \\
\hline & & & -2.278 & & \\
\hline \multirow{2}{*}{ CMP, $n(\%)$} & \multirow{2}{*}{$1279(69.2)$} & \multirow{2}{*}{$173(67.6)$} & 0.555 & \multirow{2}{*}{0.919} & \multirow{2}{*}{$0.695-1.216$} \\
\hline & & & -0.349 & & \\
\hline \multirow{2}{*}{ Neurological disease, $n(\%)$} & \multirow{2}{*}{$1276(5.5)$} & \multirow{2}{*}{$49(19.4)$} & 0.051 & \multirow{2}{*}{1.344} & \multirow{2}{*}{$0.960-1.882$} \\
\hline & & & -4.98 & & \\
\hline \multirow{2}{*}{ Psychiatric, $n(\%)$} & \multirow{2}{*}{$240(12.9)$} & \multirow{2}{*}{$31(12.1)$} & 0.683 & \multirow{2}{*}{0.92} & \multirow{2}{*}{$0.617-1.372$} \\
\hline & & & -0.167 & & \\
\hline \multirow{2}{*}{ Renal, $n(\%)$} & \multirow{2}{*}{$65(3.3)$} & \multirow{2}{*}{$5(2.0)$} & 0.189 & \multirow{2}{*}{0.545} & \multirow{2}{*}{$0.217-1.366$} \\
\hline & & & -1.727 & & \\
\hline \multirow{2}{*}{ Hepatic, $n(\%)$} & \multirow{2}{*}{$44(2.5)$} & \multirow{2}{*}{$9(3.5)$} & 0.281 & \multirow{2}{*}{1.49} & \multirow{2}{*}{$0.718-3.089$} \\
\hline & & & -1.162 & & \\
\hline \multirow{2}{*}{ Malignancy, $n(\%)$} & \multirow{2}{*}{$258(13.7)$} & \multirow{2}{*}{$30(11.7)$} & 0.32 & 0.815 & $0.545-1.220$ \\
\hline & & & -0.987 & 0.815 & $0.345-1.220$ \\
\hline
\end{tabular}

CMP cardiomyopathy, HTA hypertension

of the elderly person to increasing vulnerability [12].

Geriatric and palliative patients are especially susceptible to the development of PUs but truly independent predictive factors have yet to be conclusively established. Risk factors for PUs include older age, ethnicity, lower body weight, cognitive impairment, physical impairments, and urinary or fecal incontinence [13]. The role of other comorbid conditions that affect soft tissue integrity and healingin the development of pressure ulcers in geriatric hospitals is rarely investigated. In this case-control study, more than $90 \%$ of participants suffered from at least one comorbid condition, with cardiovascular and neurological diseases being the most prevalent.

This study also shows that and increasing number of comorbid conditions was positively associated with PU prevalence in hospitalized geriatric patients.

The presence of diabetes was associated with an increased PU prevalence. Diabetes is prevalent among geriatric patients $[7,8]$ and it is associated with increased physical and psychosocial disability. Over 100 known physiologic factors, including decreased cell and growth factor response, diminished peripheral blood flow and decreased local angiogenesis, contribute to wound healing deficiencies in individuals with diabetes [14].

Prevention of pressure ulcerations in geriatric patients is imperative to reduce patient morbidity, mortality, and overall healthcare costs. Prevention strategies for pressure ulcers begin with the identification of high-risk persons, appropriate allocation of resources, and adequate techniques of pressure relief [15]. The clinician must correct all conditions that retard the healing process, including diabetes mellitus and neurological diseases.

\section{Conclusion}

The prevention of pressure ulcers in the geriatric facilities is a constant challenge for clinical staff. Regardless of the care setting a geriatric patient is admitted to, any length of stay must be accompanied by a risk assessment for preventing PU. This evaluation includes an understanding of not only the most critical medical status, but also of any underlying comorbidities. Our results suggest that diabetes mellitus and neurological diseases may be added to existing methods to determine PU risk in the geriatric population.

\section{References}

1. European Pressure Ulcer Advisory Panel, National Pressure Ulcer Advisory Panel, Pan Pacific Pressure Injury Alliance. Prevention and Treatment of Pressure Ulcers: Quick Reference Guide. Washington, DC: National Pressure Ulcer Advisory Panel; 2009.

2. Whittington K, Patrick M, Roberts JL (2000) A national study of pressure ulcer prevalence and incidence in acute care hospitals. $J$ Wound Ostomy Continence Nurs 27: 209-215. [Crossref]

3. Lyder CH, Ayello EA (2009) Annual checkup: the CMS pressure ulcer present-onadmission indicator. Adv Skin Wound Care 22: 476-484. [Crossref]

4. Horn SD, Bender SA, Ferguson ML, Smout RJ, Bergstrom N, et al. (2004) The National Pressure Ulcer Long-Term Care Study: pressure ulcer development in long-term care residents. J Am Geriatr Soc 52: 359-367. [Crossref]

5. Donini LM, De Felice MR, Tagliaccica A, De Bernardini L, Cannella C (2005) Comorbidity, frailty, and evolution of pressure ulcers in geriatrics. Med Sci Monit 11: CR326-336. [Crossref]

6. Lindgren M, Unosson M, Ek A-C (2000) Pressure sore prevalence within a public health services area. Int J Nurs Pract 6: 333-337.

7. Jaul E (2010) Assessment and management of pressure ulcers in the elderly: current strategies. Drugs Aging 27: 311-325. [Crossref]

8. Allman RM (1997) Pressure ulcer prevalence, incidence, risk factors, and impact. Clin Geriatr Med 13: 421-436. [Crossref]

9. Bergstrom N, Braden B, Kemp M, Champagne M, Ruby E (1998) Predicting pressure ulcer risk: a multisite study of the predictive validity of the Braden Scale. Nurs Res 47: 261-269. [Crossref]

10. Allman RM (1997) Pressure ulcer prevalence, incidence, risk factors, and impact. Clin Geriatr Med 13: 421-436. [Crossref]

11. Authors Russo CA, Steiner C, Spector W (2006) Hospitalizations Related to Pressure Ulcers Among Adults 18 Years and Older, 2006: Statistical Brief \#64. Hospitalizations Related to Pressure Ulcers Among Adults 18 Years and Older, 2006: Statistical Brief \#64 . [Crossref]

12. Jaul E (2010) Assessment and management of pressure ulcers in the elderly: current strategies. Drugs Aging 27: 311-325. [Crossref]

13. Fogerty MD, Abumrad NN, Nanney L, Arbogast PG, Poulose B, et al. (2008) Risk factors for pressure ulcers in acute care hospitals. Wound Repair Regen 16: 11-18. [Crossref] 
Lenche N (2016) The influence of comorbidity on the prevalence of pressure ulcers in geriatric patients

14. Brem H, Tomic-Canic M (2007) Cellular and molecular basis of wound healing in diabetes. J Clin Invest 117: 1219-1222. [Crossref]
15. Melcher RE, Longe RL, Gelbart AO (1988) Pressure sores in the elderly. A systematic approach to management. Postgrad Med 83: 299-308. [Crossref]

Copyright: $\odot 2016$ Lenche N. This is an open-access article distributed under the terms of the Creative Commons Attribution License, which permits unrestricted use, distribution, and reproduction in any medium, provided the original author and source are credited. 